Article

\title{
Variable Wall Permeability Effects on Flow and Heat Transfer in a Leaky Channel Containing Water-Based Nanoparticles
}

\author{
Aamir Shahzad ${ }^{1}$, Wael Al-Kouz ${ }^{2}$ and Waqar A. Khan ${ }^{3, *}$ \\ 1 Department of Mathematics, COMSATS University Islamabad, Abbottabad 22060, Pakistan; \\ aamir@cuiatd.edu.pk \\ 2 Department of Mechatronics Engineering, German Jordanian University, Amman 11180, Jordan; \\ wael.alkouz@gju.edu.jo \\ 3 Department of Mechanical Engineering, College of Engineering, Prince Mohammad Bin Fahd University, \\ Al Khobar 31952, Saudi Arabia \\ * Correspondence: wkhan@pmu.edu.sa
}

Received: 8 February 2020; Accepted: 30 March 2020; Published: 3 April 2020

\begin{abstract}
This work presents the effects of variable wall permeability on two-dimensional flow and heat transfer in a leaky narrow channel containing water-based nanoparticles. The nanofluid is absorbed through the walls with an exponential rate. This situation arises in reverse osmosis, ultrafiltration, and transpiration cooling in industry. The mathematical model is developed by using the continuity, momentum, and energy equations. Using stream function, the transport equations are reduced and solved by using regular perturbation method. The expressions for stream function and temperature distribution are established, which helps in finding the components of velocity, wall shear stress, and heat transfer rate inside the channel. The results show that velocity components, temperature, wall shear stress, and rate of heat transfer are minimum at the entrance region due to the reabsorption of fluid containing nanoparticles. Additionally, with increasing volume fraction of nanoparticles, the rate of heat transfer enhances at all positions inside the channel. Titanium dioxide $\left(\mathrm{TiO}_{2}\right)$ nanoparticles show higher wall shear stress compared to copper and alumina. The streamlines confirms that all the fluid is reabsorbed before reaching the exit region of the channel for high reabsorption.
\end{abstract}

Keywords: Leaky channel; analytic solution; Brinkman number; heat transfer rate; regular perturbation method

\section{Introduction}

The study of laminar flow in tube and channel with permeable walls gained significant attention due to its engineering and industrial applications, for example, in reverse osmosis desalination, transpiration cooling boundary layer control, and design of filters [1-3]. In permeable channels, the velocity and temperature are not exactly the same as those encountered in the case of inflow of solid boundaries due to the occurrence of nonzero transverse velocity at the wall.

In the literature, the investigation of steady, laminar flow of linearly viscous (Newtonian) fluid in a permeable channel is traced back to Berman's paper [4], who analytically studied the laminar flow in a leaky channel. The Navier Stokes equations were reduced into the ordinary differential equation using a similarity transformation. The formulated equation governing the flow was solved by regular perturbation 
method for small Reynolds numbers. Sellars [5] obtained a series solution for large Reynolds numbers using the idea presented by Berman [4]. Later on, an approximate solution of flow of laminar fluid flow in permeable channel with uniform suction/injection was obtained by Yuan [6], who investigated the flow in the case of moderate to high suction or injection velocities across the walls. Terrill et al. [7] investigated the flow through permeable channel with different permeability for small Reynolds number. Expression for velocity components and pressure drop were obtained. The hydrodynamics of Newtonian fluid flow with variable wall suction for both channel and tube flow was obtained by Kozinski et al. [8]. In recent years, Muthu et al. [9-11] investigated the flow of viscous fluid in a porous channel, assuming that the bulk flow decreases with an axial distance of the channel. They obtained approximate solutions for velocity components and discussed the flow variations through graphs at different positions. Tesfahun [12] attempted the problem of slip flow of linearly viscous fluid in the permeable channel with decreasing bulk flow rate inside the channel.

The phenomenon of enhanced thermophysical properties like thermal conductivity, heat transfer coefficient, and viscosity has attracted a large number of scholars due to its applications in modern science, technology, and industry. The diluted liquid suspensions of nanoparticles are dispersed in a base fluid like water or kerosene oil to get a higher thermal performance. In the literature, different models have been suggested [13-15] for the development of advanced heat transfer fluid with significantly higher thermal conductivities than those of base fluids. Different theoretical and experimental studies of the effective thermal conductivity of dispersions that contain solid particles have been conducted. Qiang et al. [16] experimentally showed that the suspended nanoparticles remarkably enhance the heat transfer coefficient of the base fluid. Further, they noticed that about $60 \%$ for the nanofluid with 2.0 vol\% copper nanoparticles at the same Reynolds number increase the convective heat transfer coefficient. The experimental study to measure the temperature distribution and to compare the heat-pipe thermal resistance using nanofluid with silver nanoparticles was performed by Kang et al. [17]. They noticed that the nanofluid as a working medium in the heat pipe can be higher than pure water. Fotukian et al. [18] also performed an experiment and showed that the addition of small amounts of nanosized $\mathrm{CuO}$ particles to the base fluid increased heat transfer coefficients considerably. The coolant fluid is injected from one plate while the other is externally heated, which showed effective thermal conductivity and viscosity of nanofluid in research by Kandelousi et al. [19]. Magnetic nanofluid forced convective heat transfer in a lid-driven semi annulus enclosure has been investigated in the presence of a variable magnetic field by Sheikholeslami et al. [20]. Magnetohydrodynamics free convection flow of CuO-water nanofluid in a square enclosure with a rectangular heated body was investigated numerically by Sheikholeslami et al. [21]. They observed that addition of nanoparticles shows high thermal performance considering the Brownian motion effect of nanoparticles, whereas the presence of a magnetic field tries to retard convection.

As mentioned in the previous paragraph, it is noticed that nanoparticles are a wide class of materials depending on the overall shape and size of the materials, peaking the immense interest of researchers in multidisciplinary fields, and can also be utilized in bioimaging applications [22]. Further, they can be employed for drug delivery [23], chemical and biological sensing [24], gas sensing [25], carbon dioxide capturing [26], and other related applications. In the literature [8-12], there is a lack of information regarding the hydrodynamical and thermophysical properties of fluid flow through a permeable channel with reabsorption across the walls in the presence of nanoparticles. Our main objectives of this study are to develop a mathematical model describing the flow of water-based nanofluid in a leaky channel with decaying flow rate, further, the ultimate goal of this research is to discuss the hydrodynamics with heat transfer of fluid flow containing nanoparticles (copper, alumina, and titanium dioxide) in leaky channel. It is believed that this study is practical in various engineering fields, which may open new directions in the domain. 


\section{Problem Statement}

Steady, nonisothermal, laminar, viscous incompressible, and two-dimensional Newtonian fluid in a narrow long leaky channel of height $a$ and length $L$ in the presence of nanoparticles is considered. The fluid moves in the $x$-direction with an initial flow rate $Q_{0}$, which decreases exponentially along the channel, see Figure 1. Moreover, we have considered a constant temperature $T_{w}$ at the walls and the average temperature of the fluid is $T_{a}$. The channel is assumed long $(a<<L)$ enough to neglect the end effects.

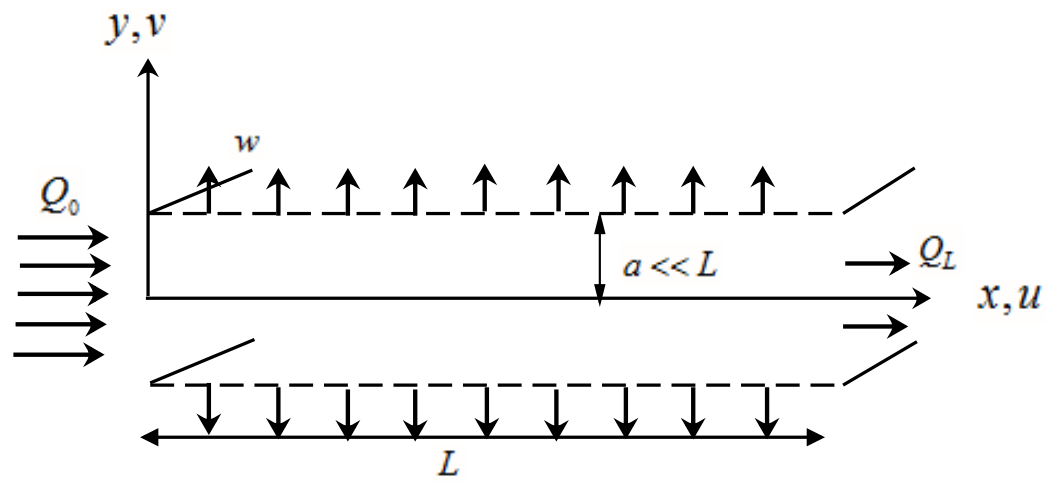

Figure 1. Geometry of the problem.

Under the above assumptions, the governing continuity, momentum, and energy equation are

$$
\begin{aligned}
\frac{\partial u}{\partial x}+\frac{\partial v}{\partial y} & =0 \\
{\left[u \frac{\partial u}{\partial x}+v \frac{\partial u}{\partial y}\right] } & =-\frac{1}{\rho_{n f}} \frac{\partial p}{\partial x}+v_{n f}\left(\frac{\partial^{2} u}{\partial x^{2}}+\frac{\partial^{2} u}{\partial y^{2}}\right), \\
{\left[u \frac{\partial v}{\partial x}+v \frac{\partial v}{\partial y}\right] } & =-\frac{1}{\rho_{n f}} \frac{\partial p}{\partial y}+v_{n f}\left(\frac{\partial^{2} v}{\partial x^{2}}+\frac{\partial^{2} v}{\partial y^{2}}\right), \\
{\left[u \frac{\partial T}{\partial x}+v \frac{\partial T}{\partial y}\right] } & =\frac{k_{n f}}{\left(\rho C_{p}\right)_{n f}}\left[\frac{\partial^{2} T}{\partial x^{2}}+\frac{\partial^{2} T}{\partial y^{2}}\right]+\frac{\mu_{n f}}{\left(\rho C_{p}\right)_{n f}}\left[4\left(\frac{\partial u}{\partial x}\right)^{2}+\left(\frac{\partial u}{\partial y}+\frac{\partial v}{\partial x}\right)^{2}\right] .
\end{aligned}
$$

The boundary conditions are

$$
\begin{array}{rlrlrl}
u & =0, \quad T=T_{w} & \text { at } & y=a, \\
v & =0, \quad \frac{\partial u}{\partial y}=0, \quad \frac{\partial T}{\partial y}=0 \quad \text { at } & y=0, \\
Q(x) & =2 w \int_{0}^{a} u d y=Q_{0} e^{-\alpha x}, & &
\end{array}
$$

where $u$ and $v$ are velocity components, $p$ is hydrodynamics pressure, and $w$ is the width of the channel. Equation (7) describes the flow rate along the channel, $Q_{0}$ is the flow rate at $x=0$, and $\alpha$ is the reabsorption parameter. Moreover, $v_{n f}=\frac{\mu_{n f}}{\rho_{n f}}$, in which $\mu_{n f}$ is the viscosity, $\rho_{n f}$ is the density, and $k_{n f}$ is the thermal conductivity of the nanofluid defined as follows [21]. 


$$
\begin{aligned}
\mu_{n f} & =\frac{\mu_{f}}{(1-\phi)^{2.5}}, \\
\rho_{n f} & =\rho_{f}(1-\phi)+\rho_{s} \phi, \\
\left(\rho C_{p}\right)_{n f} & =\left(\rho C_{p}\right)_{f}(1-\phi)+\left(\rho C_{p}\right)_{s} \phi,
\end{aligned}
$$

where $\phi$ is the nanoparticle volume fraction. The effective thermal conductivity $k_{n f}$ of the nanofluid can be approximated by the Maxwell-Garnett (MG) model [22] as

$$
\frac{k_{n f}}{k_{f}}=\frac{k_{s}+2 k_{f}-2 \phi\left(k_{f}-k_{s}\right)}{k_{s}+2 k_{f}+2 \phi\left(k_{f}-k_{s}\right)} .
$$

Using the dimensionless quantities

$$
\begin{aligned}
x^{*} & =\frac{x}{L}, \quad y^{*}=\frac{y}{a}, \quad u^{*}=\frac{a L u}{Q_{0}}, \quad v^{*}=\frac{L^{2} v}{Q_{0}}, \quad p^{*}=\frac{a^{3} p}{\mu_{f} Q_{0}}, \quad \psi^{*}=\frac{L \psi}{Q_{0}}, \quad R_{e}=\frac{Q_{0}}{v_{f} L}, \\
\theta & =\frac{T-T_{a}}{T_{w}-T_{a}}, \quad P_{e}=\frac{\rho C_{p} Q_{0}}{k_{f} a}, \quad B_{r}=\frac{\mu Q_{0}^{2}}{k_{f}\left(T_{w}-T_{a}\right) a^{2} L^{2}} \quad \delta=\frac{a}{L},
\end{aligned}
$$

where, $P_{e}, B_{r}, R_{e}$ are Peclet, Brinkman, and Reynolds numbers, respectively. Equations (1)-(4), after removing *, become

$$
\begin{aligned}
\frac{\partial u}{\partial x}+\frac{\partial v}{\partial y} & =0 \\
\delta R_{e} \bar{A}\left[u \frac{\partial u}{\partial x}+v \frac{\partial u}{\partial y}\right] & =-\frac{\partial p}{\partial x}+\frac{1}{\bar{B}}\left(\delta^{2} \frac{\partial^{2} u}{\partial x^{2}}+\frac{\partial^{2} u}{\partial y^{2}}\right) \\
\delta^{3} R_{e} \bar{A}\left[u \frac{\partial v}{\partial x}+v \frac{\partial v}{\partial y}\right] & =-\frac{\partial p}{\partial y}+\frac{\delta^{2}}{\bar{B}}\left(\delta^{2} \frac{\partial^{2} v}{\partial x^{2}}+\frac{\partial^{2} v}{\partial y^{2}}\right) \\
\delta P_{e} \bar{D}\left[u \frac{\partial \theta}{\partial x}+v \frac{\partial \theta}{\partial y}\right] & =\bar{C}\left[\delta^{2} \frac{\partial^{2} \theta}{\partial x^{2}}+\frac{\partial^{2} \theta}{\partial y^{2}}\right] \\
& +\frac{B_{r}}{\bar{B}}\left[4 \delta^{2}\left(\frac{\partial u}{\partial x}\right)^{2}+\left(\frac{\partial u}{\partial y}+\delta^{2} \frac{\partial v}{\partial x}\right)^{2}\right]
\end{aligned}
$$

where

$$
\begin{aligned}
\bar{A} & =\left[1-\phi+\rho_{s} / \rho_{f} \phi\right], \\
\bar{B} & =(1-\phi)^{2.5}, \\
\bar{C} & =\frac{k_{s}+2 k_{f}-2 \phi\left(k_{f}-k_{s}\right)}{k_{s}+2 k_{f}+\phi\left(k_{f}-k_{s}\right)}, \\
\bar{D} & =\left[1-\phi+\left(\rho C_{p}\right)_{s} /\left(\rho C_{p}\right)_{f} \phi\right] .
\end{aligned}
$$


The boundary conditions in the dimensionless form are

$$
\begin{aligned}
u & =0, \quad \theta=1 \quad \text { at } \quad y=1, \\
v & =0, \quad \frac{\partial u}{\partial y}=0, \quad \frac{\partial \theta}{\partial y}=0 \quad \text { at } \quad y=0, \\
Q(x) & =\int_{0}^{a} u d y=\frac{1}{2 \gamma} e^{-\beta x},
\end{aligned}
$$

where $\gamma=\frac{w}{L}, \beta=\alpha L$ and $P_{0}=\frac{a^{3} p_{0}}{\mu_{f} Q_{0}}$ are ratio of width to length and reabsorption parameter along the channel and entrance pressure parameters, respectively. Introducing the stream function

$$
u=\frac{\partial \psi}{\partial y}, \quad v=-\frac{\partial \psi}{\partial x} .
$$

Continuity of Equation (12) is satisfied and (14)-(16) are reduced to

$$
\begin{aligned}
R_{e} \delta \bar{A}\left[\frac{\partial \psi}{\partial y} \frac{\partial^{2} \psi}{\partial y \partial x}-\frac{\partial \psi}{\partial x} \frac{\partial^{2} \psi}{\partial y^{2}}\right] & =-\frac{\partial p}{\partial x}+\frac{1}{\bar{B}}\left(\delta^{2} \frac{\partial^{3} \psi}{\partial x^{2} \partial y}+\frac{\partial^{3} \psi}{\partial y^{3}}\right) \\
-R_{e} \delta^{3} \bar{A}\left[\frac{\partial \psi}{\partial y} \frac{\partial^{2} \psi}{\partial x^{2}}+\frac{\partial \psi}{\partial x} \frac{\partial^{2} \psi}{\partial y \partial x}\right] & =-\frac{\partial p}{\partial y}-\delta^{2} \frac{1}{\bar{B}}\left(\delta^{2} \frac{\partial^{3} \psi}{\partial x^{3}}+\frac{\partial^{2} \psi}{\partial y^{2} \partial x}\right) \\
\delta P_{e} \bar{D}\left[\frac{\partial \psi}{\partial y} \frac{\partial \theta}{\partial x}-\frac{\partial \psi}{\partial x} \frac{\partial \theta}{\partial y}\right] & =\bar{C}\left(\delta^{2} \frac{\partial^{2} \theta}{\partial x^{2}}+\frac{\partial^{2} \theta}{\partial y^{2}}\right)+\frac{B_{r}}{\bar{B}} \\
& \times\left[4 \delta^{2}\left(\frac{\partial^{2} \psi}{\partial x \partial y}\right)^{2}+\left(\frac{\partial^{2} \psi}{\partial y^{2}}-\delta^{2} \frac{\partial \psi}{\partial x^{2}}\right)^{2}\right]
\end{aligned}
$$

Eliminating the pressure from Equations (21) and (22), we obtain the following system of nonlinear PDEs:

$$
\begin{aligned}
\delta^{4} \frac{\partial^{4} \psi}{\partial x^{4}}+2 \delta^{2} \frac{\partial^{4} \psi}{\partial x^{2} \partial y^{2}}+\frac{\partial^{4} \psi}{\partial y^{4}} & =R_{e} \delta \bar{A} \bar{B}\left[\frac{\partial \psi}{\partial y}\left(\delta^{2} \frac{\partial^{3} \psi}{\partial x^{3}}+\frac{\partial^{3} \psi}{\partial y^{2} \partial x}\right)\right. \\
& \left.-\frac{\partial \psi}{\partial x}\left(\delta^{2} \frac{\partial^{3} \psi}{\partial x^{2} \partial y}+\frac{\partial^{3} \psi}{\partial y^{3}}\right)\right] \\
\delta P_{e} \bar{D}\left[\frac{\partial \psi}{\partial y} \frac{\partial \theta}{\partial x}-\frac{\partial \psi}{\partial x} \frac{\partial \theta}{\partial y}\right] & =\bar{C}\left(\delta^{2} \frac{\partial^{2} \theta}{\partial x^{2}}+\frac{\partial^{2} \theta}{\partial y^{2}}\right)+\frac{B_{r}}{\bar{B}} \\
& \times\left[4 \delta^{2}\left(\frac{\partial^{2} \psi}{\partial x \partial y}\right)^{2}+\left(\frac{\partial^{2} \psi}{\partial y^{2}}-\delta^{2} \frac{\partial \psi}{\partial x^{2}}\right)^{2}\right] .
\end{aligned}
$$

The boundary conditions are

$$
\begin{array}{rlrl}
\frac{\partial \psi}{\partial y}=0, & \psi=\frac{1}{2 \gamma} e^{-\beta x}, \quad \theta=1, \quad \text { at } \quad y=1, \\
\psi=0, & \frac{\partial^{2} \psi}{\partial y^{2}}=0, \quad \frac{\partial \theta}{\partial y}=0, & \text { at } \quad y=0 .
\end{array}
$$

The above system of equations along with boundary conditions is nonlinear PDEs, with inhomogeneous boundary conditions, capable of describing the flow of Newtonian fluid through a permeable channel containing nanoparticles. The solution to the system is solved by the perturbation method. 
The perturbation method $[27,28]$ is one of the well-known methods that produces solutions for small parameters in the form of series. The convergence criteria of the series solutions by this technique is explained in [27]. The solutions of the modeled problem are explained in the next section.

\section{Solution of the Problem}

For the solution of Equations (24) and (25) along with boundary conditions defined in Equations (26) and (27), $\psi$ and $\theta$ are assumed in a standard power series by taking $\delta$ a small parameter of the form

$$
\begin{aligned}
\psi & =\delta^{0} \psi_{0}+\delta^{1} \psi_{1}+\mathrm{O}(\delta)^{2} \ldots \\
\theta & =\delta^{0} \theta_{0}+\delta^{1} \theta_{1}+\mathrm{O}(\delta)^{2} \ldots
\end{aligned}
$$

Substituting Equations (28) and (29) in Equations (23) and (24) along with boundary conditions (25) and (26), a system of equations is obtained up to first-order as follows.

\subsection{Zeroth-Order Problem and Solution}

On equating the coefficients of $\delta^{0}$ on both sides of Equations (23)-(26), the zeroth-order system is obtained as follows:

$$
\begin{aligned}
& \frac{\partial^{4} \psi_{0}}{\partial y^{4}}=0 \\
& \frac{\partial^{2} \theta_{0}}{\partial y^{2}}=-\frac{B_{r}}{\bar{C} \bar{B}}\left(\frac{\partial^{2} \psi_{0}}{\partial y^{2}}\right)^{2},
\end{aligned}
$$

and the boundary conditions are

$$
\begin{array}{rlrl}
\frac{\partial \psi_{0}}{\partial y} & =0, & \psi_{0}=\frac{1}{2 \gamma} e^{-\beta x}, \quad \theta_{0}=1, & \text { at } y=1, \\
\psi_{0}=0, & \frac{\partial^{2} \psi_{0}}{\partial y^{2}}=0, \quad \frac{\partial \theta_{0}}{\partial y}=0, & \text { at } y=0 .
\end{array}
$$

The set of solutions of the zeroth-order system is obtained as

$$
\begin{aligned}
\psi_{0}(x, y) & =-\frac{1}{4} \frac{y^{3}}{\gamma e^{\beta x}}+\frac{3}{4} \frac{y}{\gamma e^{\beta x}}, \\
\theta_{0}(x, y) & =-\frac{3}{16} \frac{B_{r} e^{-2 \beta x} y^{4}}{\bar{C} \bar{B} \gamma^{2}}+\frac{1}{16} \frac{16 \bar{C} \bar{B} \gamma^{2} e^{2 \beta x}+3 B_{r}}{\bar{C} \bar{B} \gamma^{2} e^{2 \beta x}},
\end{aligned}
$$

which strongly depends upon the reabsorption as well as the heat conduction from a wall to a flowing viscous, $\left(B_{r}\right)$.

\subsection{First-Order Problem and Solution}

On comparing the coefficients of $\delta^{1}$ on both sides of Equations (23)-(26), the first-order system is obtained as follows:

$$
\begin{aligned}
& \frac{\partial^{4} \psi_{1}}{\partial y^{4}}=R_{e} \bar{A} \bar{B}\left[\frac{\partial \psi_{0}}{\partial y} \frac{\partial^{3} \psi_{0}}{\partial y^{2} \partial x}-\frac{\partial \psi_{0}}{\partial x} \frac{\partial^{3} \psi_{0}}{\partial y^{3}}\right], \\
& \frac{\partial^{2} \theta_{0}}{\partial y^{2}}=-2 \frac{B_{r}}{\bar{C} \bar{B}}\left(\frac{\partial^{2} \psi_{0}}{\partial y^{2}}\right)\left(\frac{\partial^{2} \psi_{1}}{\partial y^{2}}\right)+\frac{P_{e} \bar{D}}{\bar{C}}\left[\frac{\partial \psi_{0}}{\partial y} \frac{\partial \theta_{0}}{\partial x}-\frac{\partial \psi_{0}}{\partial x} \frac{\partial \theta_{0}}{\partial y}\right],
\end{aligned}
$$


and the boundary condition are

$$
\begin{aligned}
\frac{\partial \psi_{1}}{\partial y}=0, & \psi_{1}=0, \quad \theta_{1}=0, \quad \text { at } y=1, \\
\psi_{1}=0, & \frac{\partial^{2} \psi_{1}}{\partial y^{2}}=0, \quad \frac{\partial \theta_{1}}{\partial y}=0, \quad \text { at } \quad y=0 .
\end{aligned}
$$

The set of solutions of the first-order system is obtained as

$$
\begin{aligned}
\psi_{1}(x, y) & =-\frac{R_{e} \bar{A} \bar{B} e^{-2 \beta x} y^{7} \beta}{1120 \gamma^{2}}+\frac{3 R_{e} \bar{A} \bar{B} \beta y^{3}}{1120 \gamma^{2} e^{2 \beta x}}-\frac{R_{e} \bar{A} \bar{B} \beta y}{560 \gamma^{2} e^{2 \beta x}} \\
\theta_{1}(x, y) & =-\frac{9 \bar{A} B_{r} R_{e} \beta y^{8}}{4480 \bar{C} \gamma^{3}\left(e^{\beta x}\right)^{3}}-\frac{3 P_{e} \bar{D} \beta B_{r} y^{8}}{1792 \bar{C}^{2} \gamma^{3} \bar{B}\left(e^{\beta x}\right)^{3}}-\frac{3 P_{e} \bar{D} \beta B_{r} y^{6}}{320 \bar{C}^{2} \gamma^{3} \bar{B}\left(e^{\beta x}\right)^{3}} \\
& +\frac{9 \bar{A} B_{r} R_{e} \beta y^{4}}{2240 \bar{C} \gamma^{3}\left(e^{\beta x}\right)^{3}}+\frac{3 P_{e} \bar{D} \beta B_{r} y^{4}}{128 \bar{C}^{2} \gamma^{3} \bar{B}\left(e^{\beta x}\right)^{3}}-\frac{9 P_{e} \bar{D} y^{2} \beta B_{r}}{64 \bar{C}^{2} \gamma^{3} \bar{B}\left(e^{\beta x}\right)^{3}} \\
& -\frac{9 \bar{A} B_{r} R_{e} \beta}{4480 \bar{C} \gamma^{3}\left(e^{\beta x}\right)^{3}}+\frac{1149 P_{e} \bar{D} \beta B_{r}}{8960 \bar{C}^{2} \gamma^{3} \bar{B}\left(e^{\beta x}\right)^{3}} .
\end{aligned}
$$

It is noticed that Equation (41) depends upon the $P_{e}$. The stream function and temperature distributions up to first order can be obtained by substituting zeroth and first-order solutions in Equations (28) and (29).

$$
\begin{aligned}
\psi & =-\frac{1}{4} \frac{y^{3}}{\gamma e^{\beta x}}+\frac{3}{4} \frac{y}{\gamma e^{\beta x}}+\frac{\delta R_{e} \beta}{\gamma^{2}}\left[-\frac{\bar{A} \bar{B} y^{7}}{1120 e^{2 \beta x}}+\frac{3 \bar{A} \bar{B} y^{3}}{1120 e^{2 \beta x}}-\frac{\bar{A} \bar{B} \beta y}{560 e^{2 \beta x}}\right], \\
\theta & =-\frac{3}{16} \frac{B_{r} e^{-2 \beta x} y^{4}}{\bar{C} \bar{B} \gamma^{2}}+\frac{1}{16} \frac{16 \bar{C} \bar{B} \gamma^{2} e^{2 \beta x}+3 B_{r}}{\bar{C} \bar{B} \gamma^{2} e^{2 \beta x}} \\
& +\delta\left[-\frac{9 \bar{A} B_{r} R_{e} \beta y^{8}}{4480 \bar{C} \gamma^{3}\left(e^{\beta x}\right)^{3}}-\frac{3 P_{e} \bar{D} \beta B_{r} y^{8}}{1792 \bar{C}^{2} \gamma^{3} \bar{B}\left(e^{\beta x}\right)^{3}}-\frac{3 P_{e} \bar{D} \beta B_{r} y^{6}}{320 \bar{C}^{2} \gamma^{3} \bar{B}\left(e^{\beta x}\right)^{3}}\right. \\
& +\frac{9 \bar{A} B_{r} R_{e} \beta y^{4}}{2240 \bar{C} \gamma^{3}\left(e^{\beta x}\right)^{3}}+\frac{3 P_{e} \bar{D} \beta B_{r} y^{4}}{128 \bar{C}^{2} \gamma^{3} \bar{B}\left(e^{\beta x}\right)^{3}}-\frac{9 P_{e} \bar{D} y^{2} \beta B_{r}}{64 \bar{C}^{2} \gamma^{3} \bar{B}\left(e^{\beta x}\right)^{3}} \\
& \left.-\frac{9 \bar{A} B_{r} R_{e} \beta}{4480 \bar{C} \gamma^{3}\left(e^{\beta x}\right)^{3}}+\frac{1149 P_{e} \bar{D} \beta B_{r}}{8960 \bar{C}^{2} \gamma^{3} \bar{B}\left(e^{\beta x}\right)^{3}}\right] .
\end{aligned}
$$

The velocity components, flow rate, wall shear stress, and heat transfer coefficient can be established using the following relation:

$$
\begin{aligned}
u(x, y) & =\frac{\partial \psi}{\partial y}, \quad v(x, y)=-\frac{\partial \psi}{\partial x}, \quad \tau=\frac{a^{2} L \tau_{w}}{\mu_{f} Q_{0}}=-\left.\frac{1}{\bar{A}}\left(\frac{\partial^{2} \psi}{\partial y^{2}}-\delta^{2} \frac{\partial^{2} \psi}{\partial x^{2}}\right)\right|_{y=1}, \\
q & =\frac{\dot{q} a^{2}}{k_{f}\left(T_{w}-T_{a}\right)}=-\bar{C}\left(\delta \frac{\partial \theta}{\partial x}+\frac{\partial \theta}{\partial y}\right)_{y=1},
\end{aligned}
$$

where $\tau$ is dimensionless wall shear stress and $q$ is dimensionless heat transfer rate at the wall. 


\section{Results and Discussion}

In the present section, a complete discussion of the flow and heat transfer of viscous fluid flow in a leaky channel with variable wall permeability is presented in the presence of water-based nanoparticles, i.e., copper $(\mathrm{Cu})$, alumina $\left(\mathrm{Al}_{2} \mathrm{O}_{3}\right)$, and titanium dioxide $\left(\mathrm{TiO}_{2}\right)$. The effects of several parameters like $\mathrm{Cu}$-nanoparticles volume fraction $(\phi)$, reabsorption parameter $\beta$, and Brinkman number $B_{r}$ on velocity components $(u, v)$, temperature distribution $(\theta)$, wall shear stress $(\tau)$, and heat transfer rate $(q)$ are studied at different positions inside the channel graphically in Figures 2-14. Further, the variation of three different nanoparticles $(\mathrm{Cu}),\left(\mathrm{Al}_{2} \mathrm{O}_{3}\right)$, and $\left(\mathrm{TiO}_{2}\right)$ are also displayed for dimensionless longitudinal velocity, transverse velocity, and temperature distribution at the middle region of the channel with water as a base fluid, as shown in Figure 6. Moreover, the variation of these nanoparticles on dimensionless wall shear stress and heat transfer rate are shown in Figure 7. The thermophysical properties of the base fluid and the three different nanoparticles $(\mathrm{Cu}),\left(\mathrm{Al}_{2} \mathrm{O}_{3}\right)$, and $\left(\mathrm{TiO}_{2}\right)$ are listed in Table 1 .

Table 1. Thermophysical properties of base fluid and nanoparticles $[29,30]$.

\begin{tabular}{ccccc}
\hline Physical Properties & Base Fluid & $\mathbf{C u}$ & $\mathbf{A l}_{\mathbf{2}} \mathbf{O}_{\mathbf{3}}$ & $\mathbf{T i O}_{\mathbf{2}}$ \\
\hline$\rho\left(k g / m^{3}\right)$ & 997 & 8933 & 3970 & 4250 \\
$C p(\mathrm{~J} / \mathrm{kgK})$ & 4179 & 385 & 765 & 686.2 \\
$k(W / m K)$ & 0.613 & 400 & 40 & 4.9538 \\
\hline
\end{tabular}

Figure 2 is plotted to analyze the effect of $\phi$ in longitudinal velocity $u(x, y)$ profiles at different regions, such as entrance $(x=0)$, middle $(x=0.5)$, and exit $(x=0.9)$. It is noted that the profile $u(x, y)$ is parabolic and is higher at the entrance region compared to the middle and exit regions. With increasing $\phi$, the profile $u(x, y)$ shows increasing behavior at three different regions. In addition, maximum velocity profile of $u(x, y)$ can be observed at the center of the channel. In Figure 3 , it is noticed that transverse velocity $v(x, y)$ is higher at the entrance as compared to the middle and exit regions, see Figure $3 b$,c. With an increase in $\phi$, the velocity in $y$-direction increases and maximum velocity is noticed at the walls of the channel.
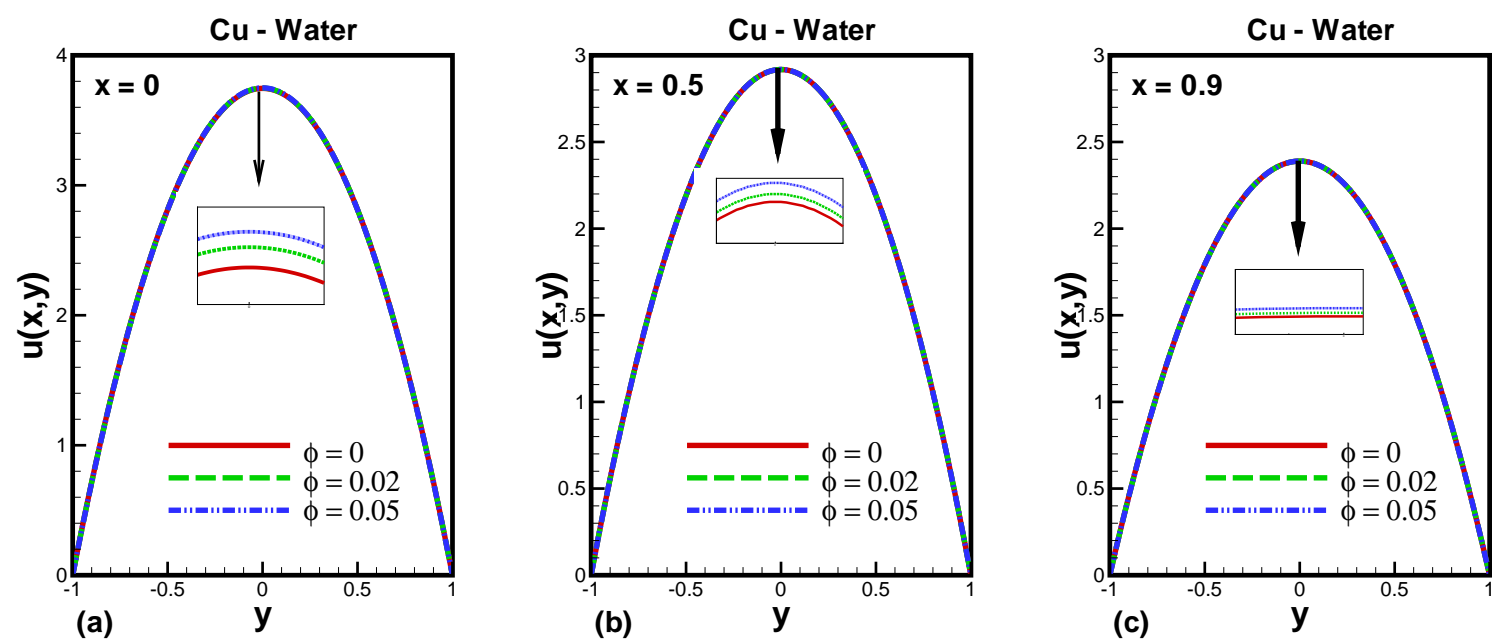

Figure 2. Effect of copper nanoparticle volume fraction $\phi$ on dimensionless longitudinal velocity at the (a) entrance, (b) middle, and (c) exit regions of the channel, when $\beta=0.5, \delta=0.2, R_{e}=1$, and $\gamma=0.2$. 

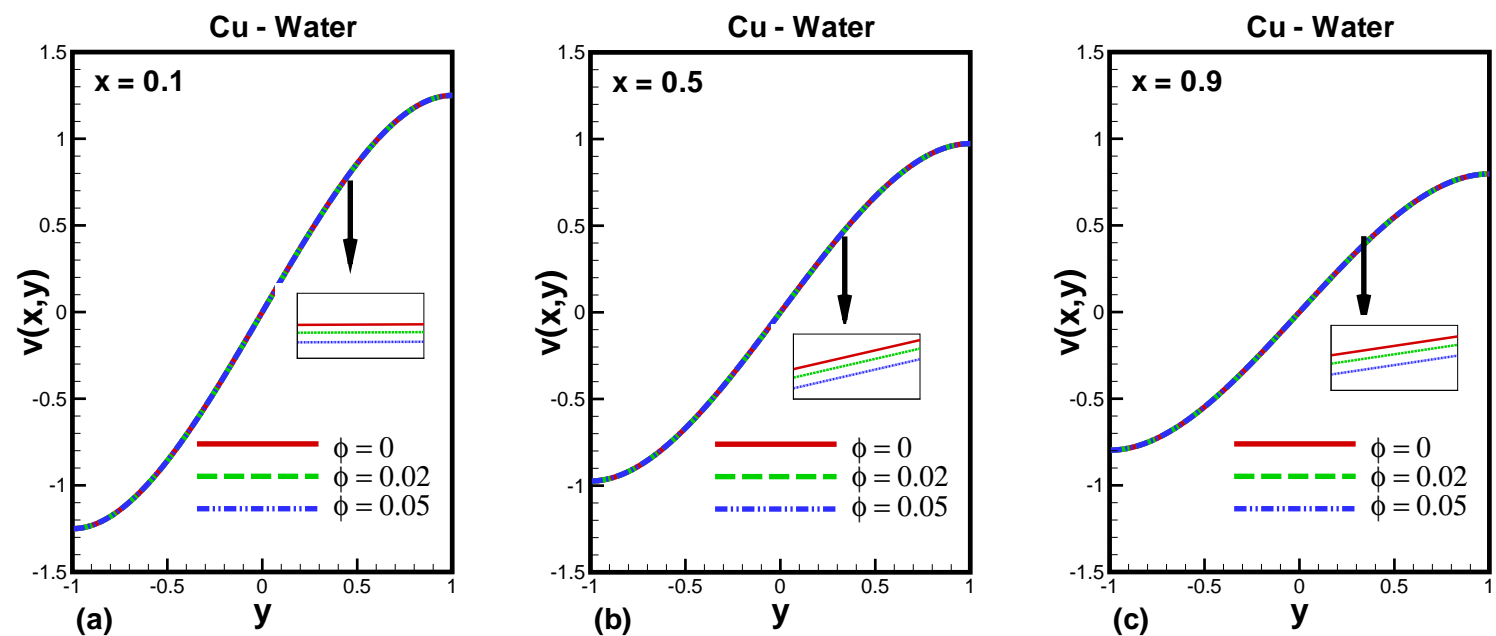

Figure 3. Effect of copper nanoparticle volume fraction $\phi$ on dimensionless transverse velocity at the (a) entrance, (b) middle, and (c) exit regions of the channel, when $\beta=0.5, \delta=0.2, R_{e}=1$, and $\gamma=0.2$.

The effect of Cu-nanoparticles volume fraction $\phi$ on temperature profile $\theta(x, y)$ at the entrance, middle, and exit regions are shown in Figure 4 . The increase in $\phi$ tends to increase the temperature profile at all three regions inside the channel. Moreover, the temperature profile at the entrance region is observed to be higher compared to the middle and exit regions of the channel. This happens due to leakage of fluid inside the channel, while addition of volume fraction enhances the temperature profile remarkably.
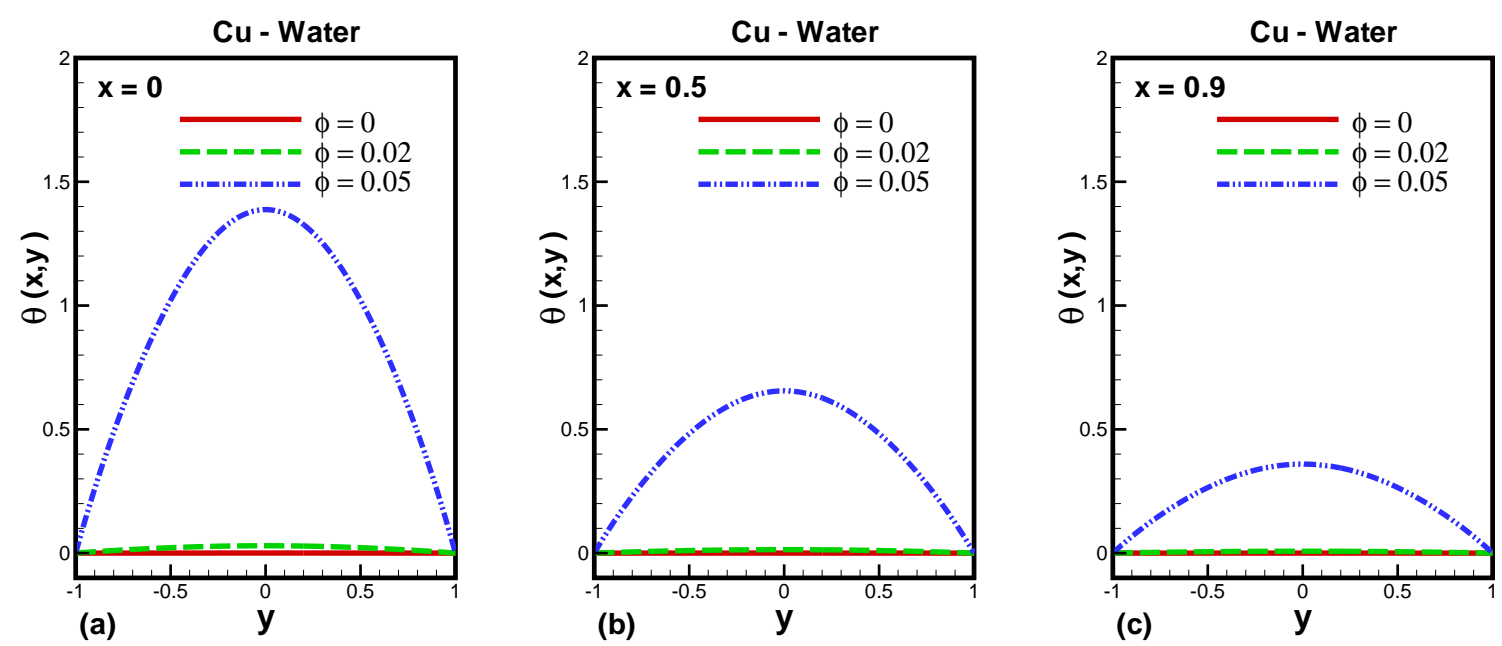

Figure 4. Effect of copper nanoparticle volume fraction $\phi$ on dimensionless temperature at the (a) entrance, (b) middle, and (c) exit regions of the channel, when $\beta=0.5, B_{r}=6, P_{e}=1, \delta=0.2, R_{e}=1$, and $\gamma=0.2$.

The variations in the wall shear stress and the heat transfer rate with the governing parameter $\phi$ are presented in Figure 5a,b. Figure 5a shows that when increasing the strength of $\phi$, the wall shear stress decreases, see Figure 5a. Furthermore, it is noted that its profile decreases along the channel due to the reason of fluid leakage across the walls of the channel. Figure $5 \mathrm{~b}$ shows that the heat transfer rate also declines along the channel from entrance to exit; with increasing $\phi$, its profile increases. Maximum heat transfer rate is noticed at the entrance of the channel. 

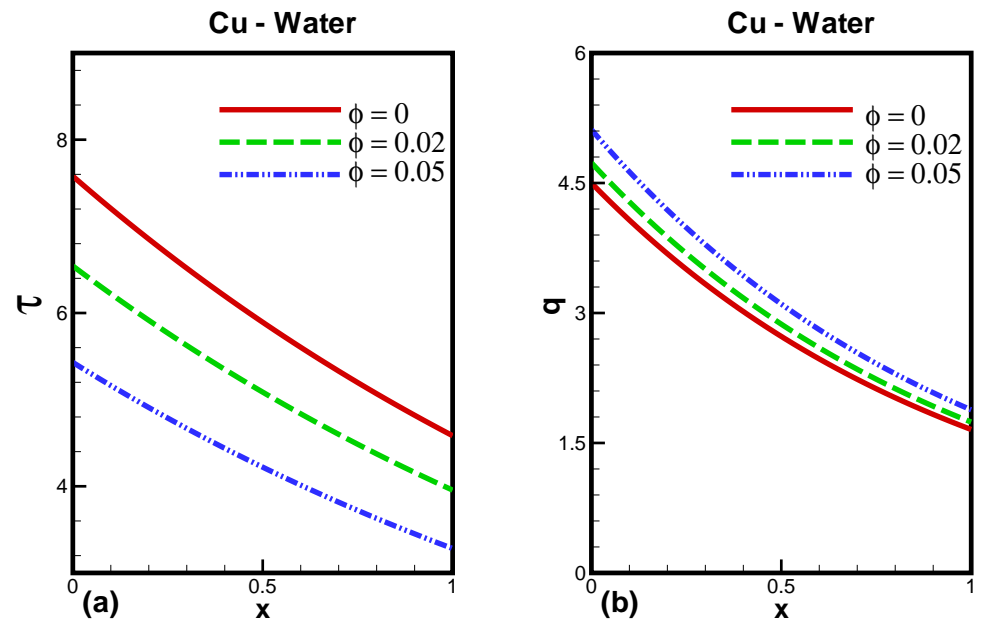

Figure 5. Effect of copper nanoparticle volume fraction $\phi$ on dimensionless (a) wall shear stress and (b) heat transfer rate at the wall, when $\beta=1, R_{e}=1, \delta=0.2, B_{r}=6, P_{e}=1$, and $\gamma=0.2$.

In Figure 6, the variation of different nanoparticles, such as $(\mathrm{Cu}),\left(\mathrm{Al}_{2} \mathrm{O}_{3}\right)$, and $\left(\mathrm{TiO}_{2}\right)$ on dimensionless longitudinal velocity, transverse velocity, and temperature distribution at the middle region-i.e., $(x=0.5)$ of the channel-with water as a base fluid are plotted. Interestingly, it is noted that the velocity components and wall shear stress have a similar nature, while temperature and heat transfer have same variations. The velocity profiles and wall shear stress of for water-based $\mathrm{Al}_{2} \mathrm{O}_{3}$ nanoparticles is high in magnitude as compared to others, like copper $(\mathrm{Cu})$ and titanium dioxide $\left(\mathrm{TiO}_{2}\right)$, see Figures $6 \mathrm{a}, \mathrm{b}$ and $7 \mathrm{a}$. The profile of temperature and heat transfer of water-based $\left(\mathrm{TiO}_{2}\right)$ nanoparticles is high in magnitude as compared to others, see Figures $6 \mathrm{c}$ and $7 \mathrm{~b}$.
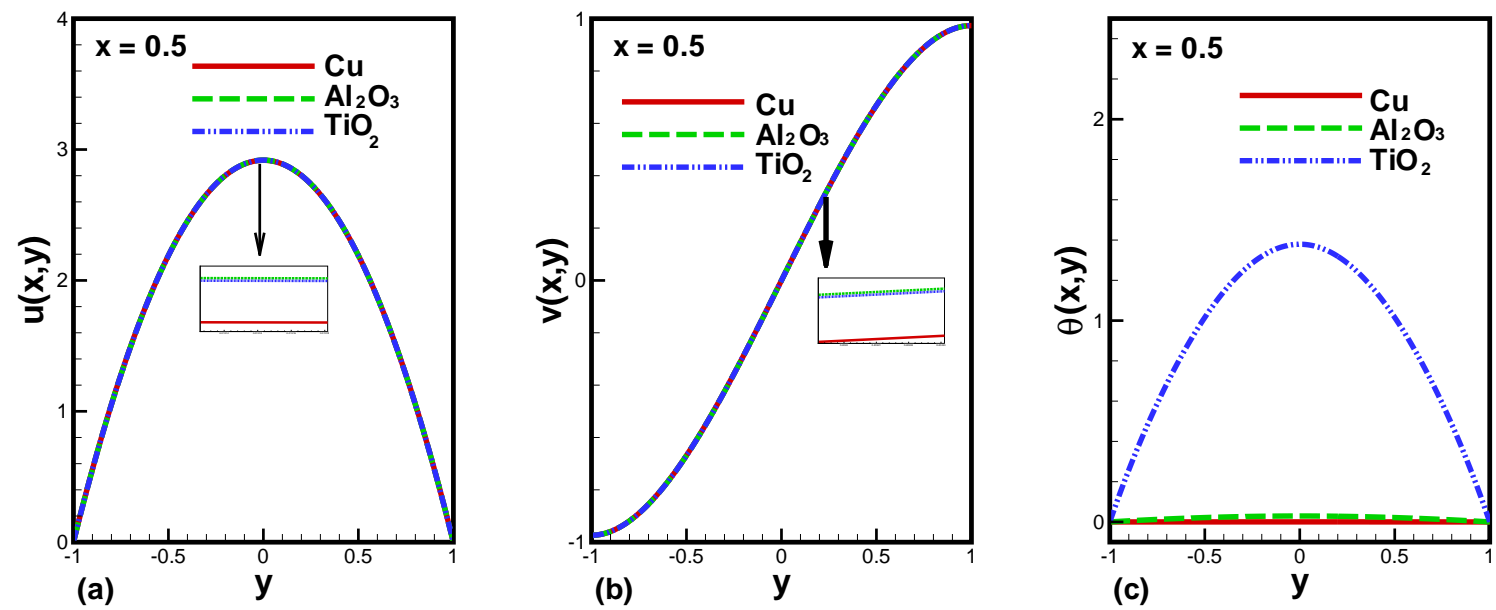

Figure 6. Variation of different nanoparticles on dimensionless (a) longitudinal, (b) transverse velocities, and (c) temperature profile at the middle region of the channel, when $\beta=0.5, \phi=0.05, B_{r}=6, P_{e}=1$, $\delta=0.2, R_{e}=1$, and $\gamma=0.2$. 

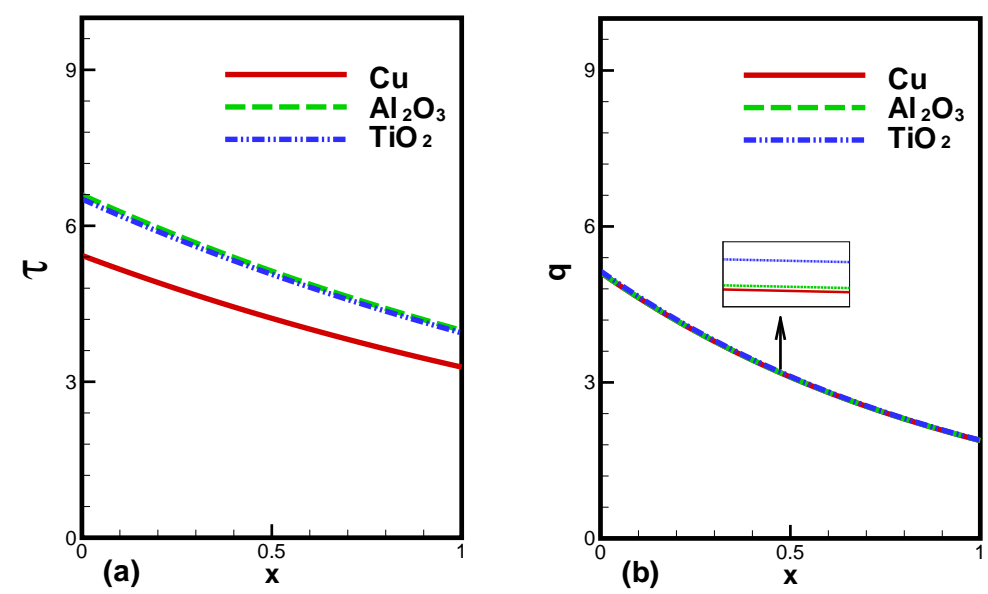

Figure 7. Variation of different nanoparticles on dimensionless (a) wall shear stress and (b) heat transfer rate, when $\beta=1, R_{e}=1, \delta=0.2, B_{r}=6, P_{e}=1, \phi=0.05$, and $\gamma=0.2$.

The effects of reabsorption parameter $\beta$ on velocity component $u(x, y)$ of water-based copper nanoparticles at the entrance, middle, and exit regions are shown in Figure 8 . At the entrance, no effects are observed because the permeability starts after the entrance $(x>0)$, see Figure $8 \mathrm{a}$. It is noted that $u(x, y)$ is parabolic and is higher at the entrance compared to the middle and exit regions of the channel. From Figure $8 \mathrm{~b}, \mathrm{c}$, we observed that with increasing $\beta$, the profile $u(x, y)$ decreases due to fluid leakage across the walls.

From Figure 9, effect of $\beta$ on transverse velocity $v(x, y)$ at the entrance, middle, and exit of the channel are plotted. The profile $v(x, y)$ increases with increasing $\beta$. Maximum transverse velocity $v(x, y)$ is higher at the entrance region compared to the middle and exit regions of the channel.
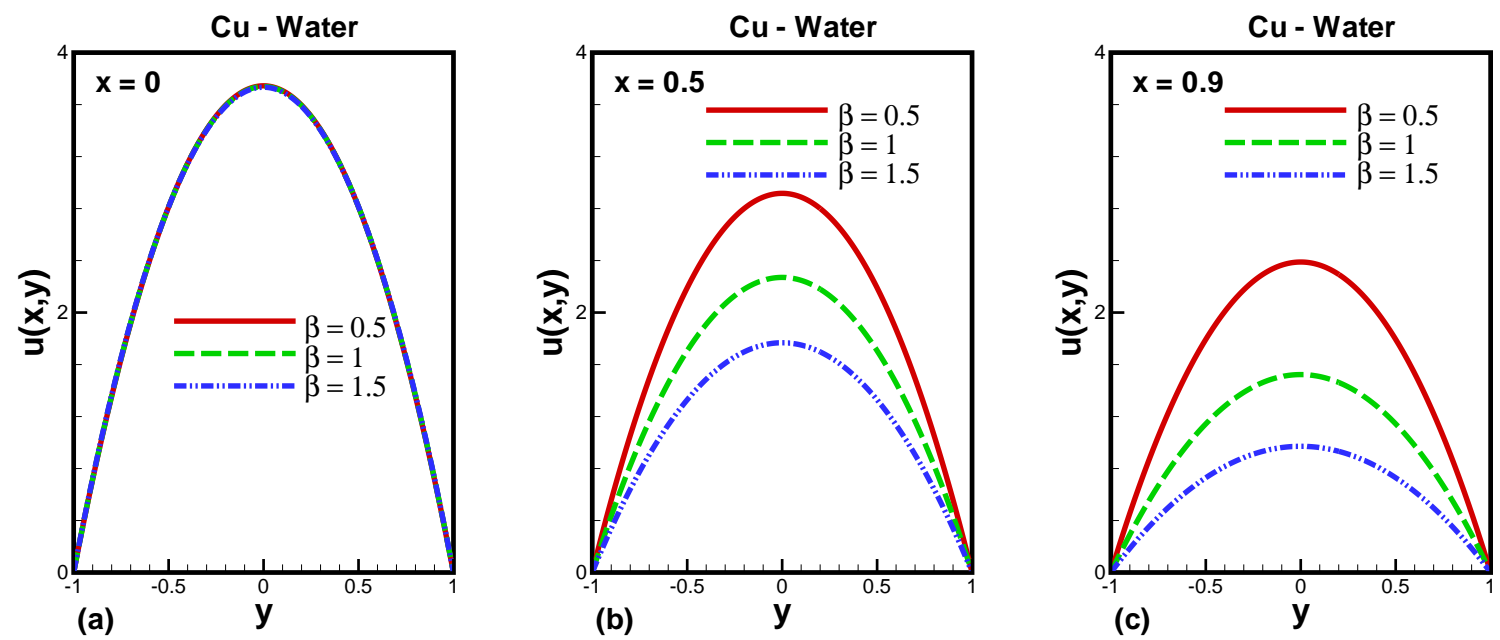

Figure 8. Effect of $\beta$ on dimensionless longitudinal velocity at the (a) entrance, (b) middle, and (c) exit regions of the channel, when $\phi=0.05, \delta=0.2$, and $\gamma=0.2$. 

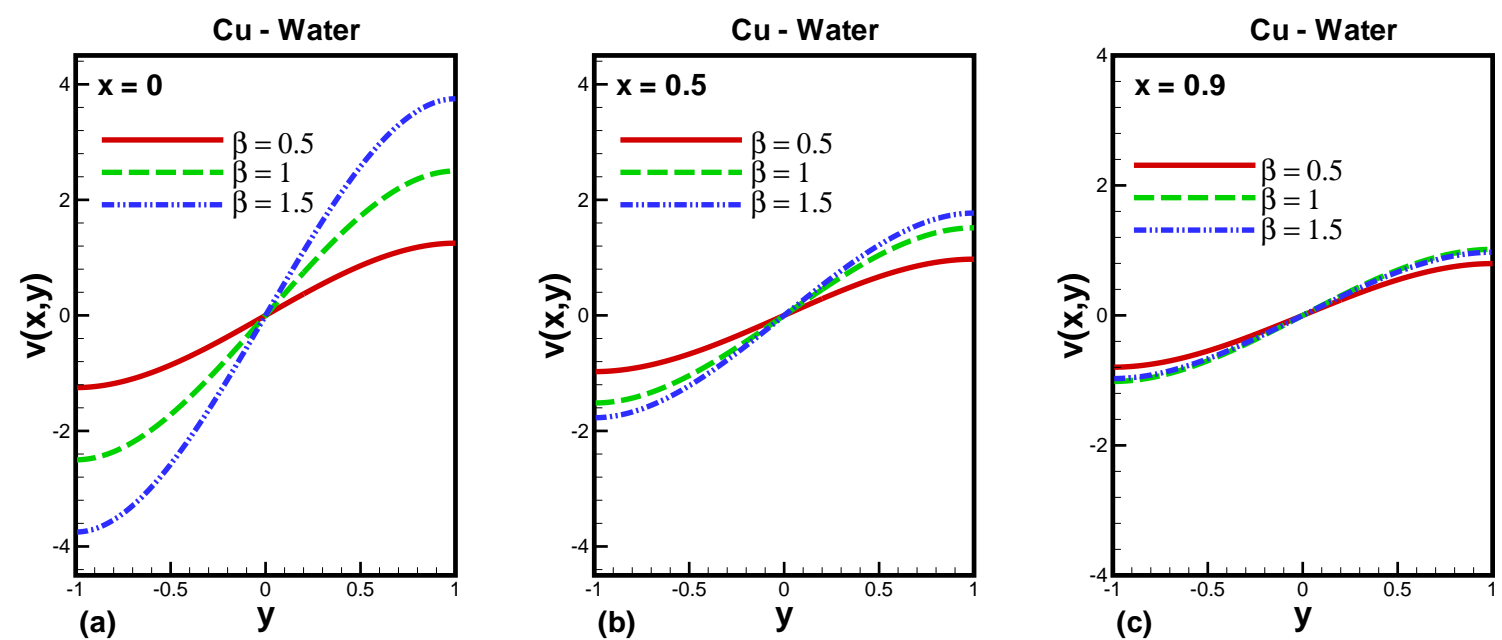

Figure 9. Effect of $\beta$ on dimensionless transverse velocity at the (a) entrance, (b) middle, and (c) exit regions of the channel, when $\phi=0.05, \delta=0.2$, and $\gamma=0.2$.

Figure 10 illustrates the dimensionless temperature at the entrance, middle, and exit regions of the channel. When increasing the strength of $\beta$, the temperature increases at the different regions. At the entrance, the temperature profile is very high compared to middle and exit region. The leakage of fluid across the walls causes low profile of temperature, see Figure 10b,c. From Figure 11, we noted that wall shear stress and heat transfer decays along the channel due to fluid leakage, also, maximum wall shear stress and heat transfer are maximum at the entrance of the channel.
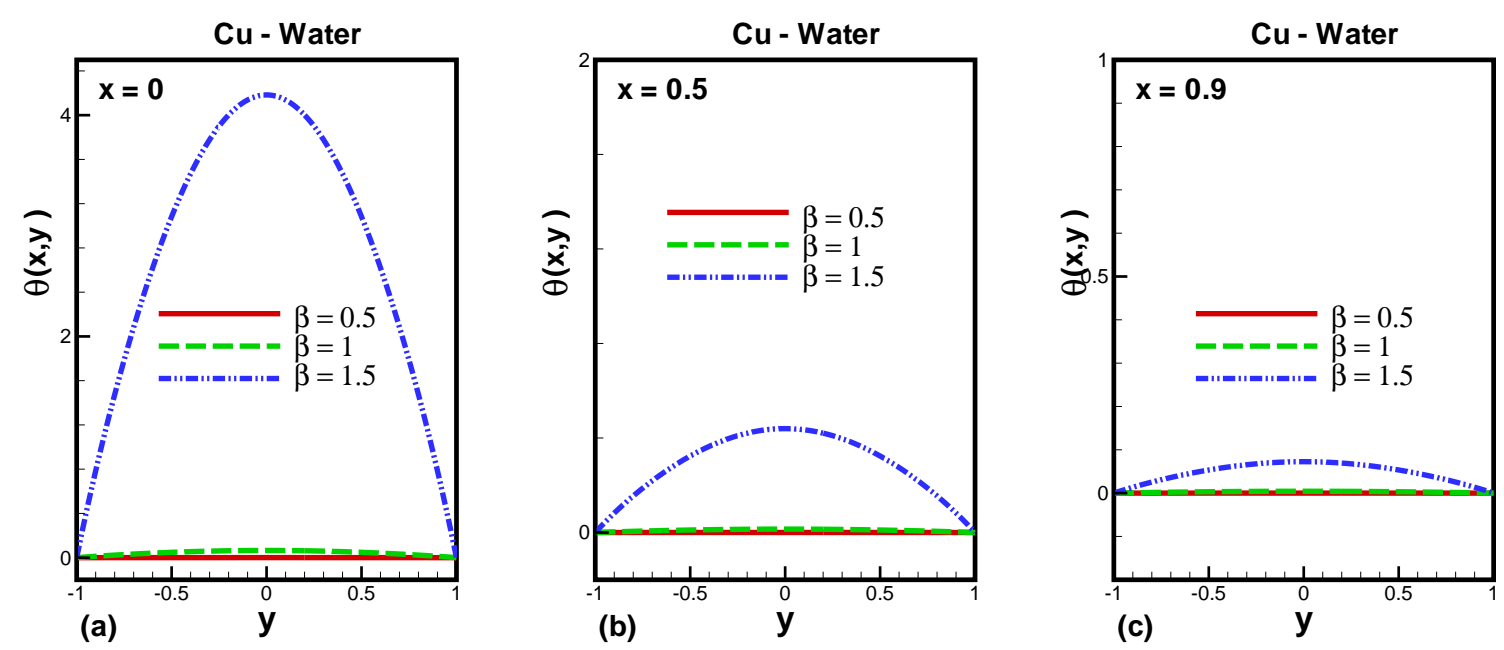

Figure 10. Effect of $\beta$ on dimensionless temperature distribution at the (a) entrance, (b) middle, and (c) exit regions of the channel, when $\phi=0.05, \delta=0.2, P_{e}=1, B_{r}=6, \delta=0.2$, and $\gamma=0.2$.

The behavior of the Brinkman number $B_{r}$ on temperature distribution at three different regions is shown in Figure 12. With increasing $B_{r}$, the temperature increases at these different regions as well as the temperature profile at the entrance are higher compared to middle and exit of the channel. The heat transfer enhances with increasing $B_{r}$, it also decays along the channel because of fluid leakage across the walls. 

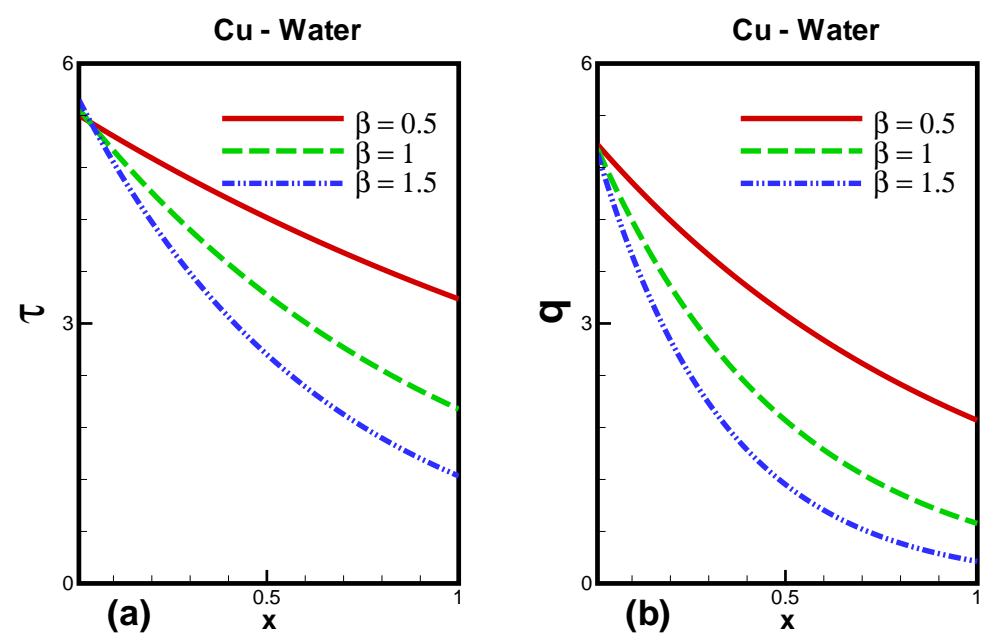

Figure 11. Effect of $\beta$ on dimensionless on dimensionless (a) wall shear stress and (b) heat transfer rate, when $\phi=0.05, R_{e}=1, \delta=0.2, B_{r}=6, P_{e}=1$, and $\gamma=0.2$.
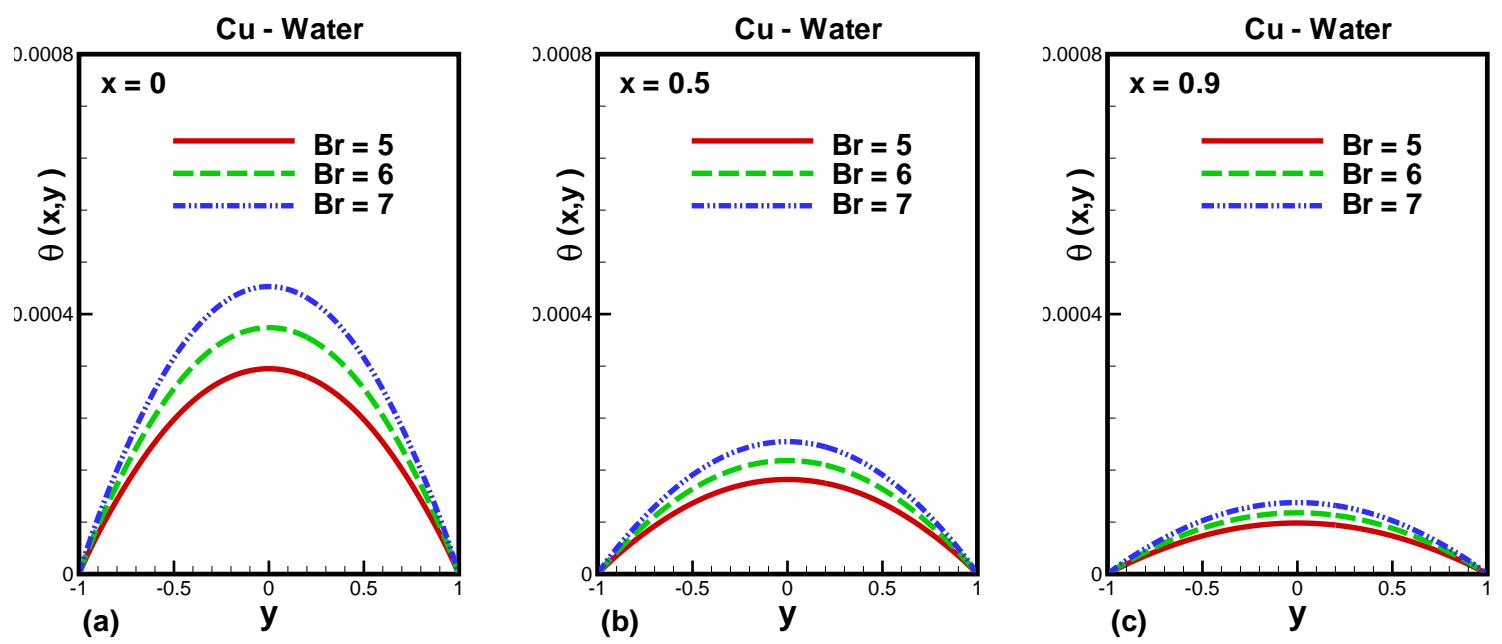

Figure 12. Effect of $B_{r}$ on dimensionless temperature distribution at the (a) entrance, (b) middle, and (c) exit regions of the channel, when $\phi=0.05, \delta=0.2, P_{e}=1, \beta=0.5, \delta=0.2$, and $\gamma=0.2$.

Lastly, Figure 14 is plotted to study the influence of the reabsorption on the streamlines pattern. The streamlines show a path followed by a fluid particle during its motion with the flow where mass cannot cross it. The streamline pattern is noticed better for lower values of reabsorption numbers, while for high reabsorption number, fluid cannot reach the exit region of the channel, see Figure 14. 


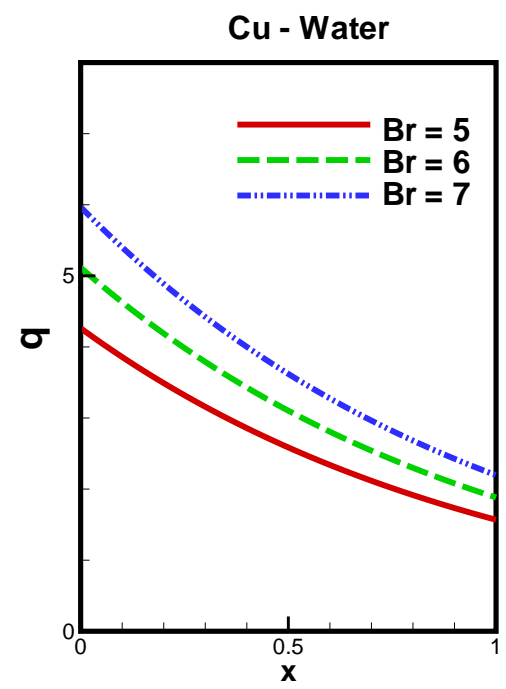

Figure 13. Effect of $B_{r}$ on dimensionless on dimensionless heat transfer, when $\phi=0.05, R_{e}=1, \delta=0.2$, $\beta=0.5, P_{e}=1$, and $\gamma=0.2$.

\section{Concluding Remarks}

The present work addresses the flow and heat transfer on viscous fluid flow with water-based nanoparticles, such as copper $(\mathrm{Cu})$, alumina $\left(\mathrm{Al}_{2} \mathrm{O}_{3}\right)$, and titanium dioxide $\left(\mathrm{TiO}_{2}\right)$, in a permeable narrow channel. Using stream function, the number of nonlinear PDEs are reduced. The system of the these PDEs are linearized using regular perturbation method. The impact of various emerging physical parameters on components of velocity, temperature profile, wall shear stress, and rate of heat transfer have been studied graphically. The important findings of the study are given below:

1. Velocity components, temperature, wall shear stress, and heat transfer rate are higher at the entrance compared to middle and exit regions of the channel due to fluid leakage across the walls.

2. Increasing the strength of nanoparticles volume fraction causes enhanced velocity components, temperature, wall shear stress, and rate of heat transfer at all positions inside the channel.

3. Titanium dioxide nanofluid has higher values for velocity component and wall shear stress compared to copper and alumina, while opposite behavior is noticed for temperature.

4. Reabsorption parameter reduces the longitudinal velocity, while increasing the transverse velocity at all regions inside the the channel.

5. Higher values of reabsorption parameter and Brinkman number enhance dimensionless temperature at the entrance, middle, and exit regions.

6. Maximum longitudinal velocity is observed in the center line, while maximum transverse velocity is noticed at the surface of the wall.

7. Streamlines indicate high fluid reabsorption with increasing reabsorption parameter. 

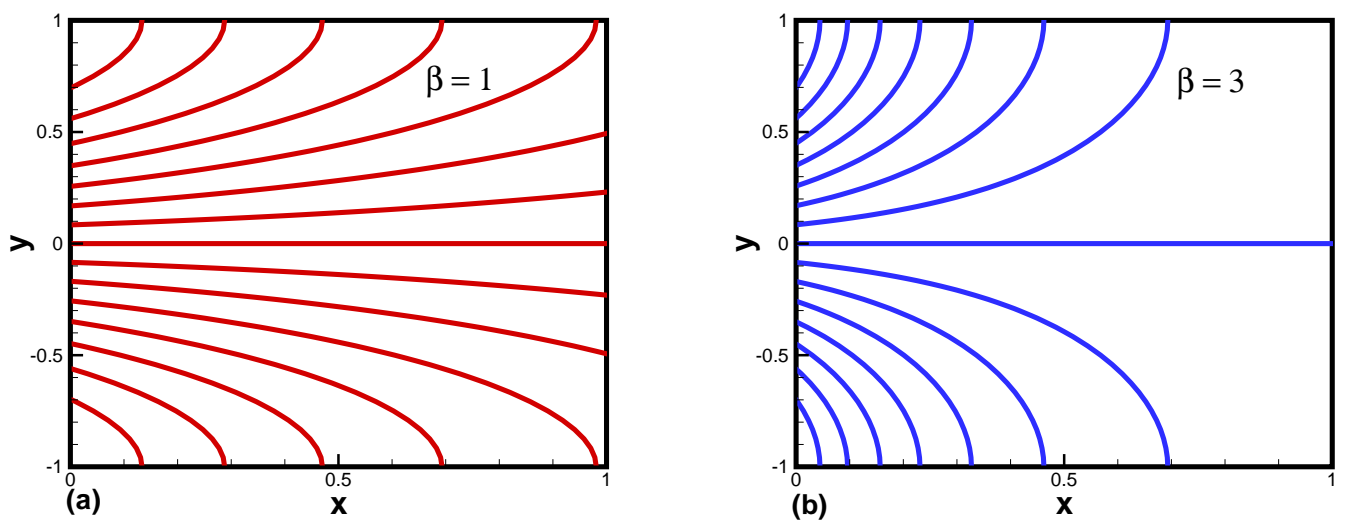

Figure 14. Streamlines behavior for water-based copper nanoparticle when (a) $\beta=1$ and (b) $\beta=3$ and other parameters are $R_{e}=1, \delta=0.2, \phi=0.05$, and $\gamma=0.2$.

Author Contributions: A.S.: Formulation; Writing-Original draft preparation; Software; Results and discussion. W.A.K.: Conceptualization; Methodology; Review; Validation. W.A.-K.: Funding acquisition; Reviewing and Editing; Project Management. All authors have read and agreed to the published version of the manuscript.

Funding: This research received no external funding.

Conflicts of Interest: There is no actual or potential conflict of interest including any financial, personal, or other relationships with other people or organizations.

\section{References}

1. Sheikholeslami, M.; Hatami, M.; Ganji, D.D. Analytical investigation of MHD nanofluid flow in a semi-porous channel. Powder Technol. 2013, 246, 327-336. [CrossRef]

2. Andoh, Y.H.; Lips, B. Prediction of porous walls thermal protection by effusion or transpiration cooling. An analytical approach. Appl. Therm. Eng. 2003, 23, 1947-1958. [CrossRef]

3. Runstedtler, A. On themodi fied Stefan-Maxwell equation for isothermal multi component gaseous diffusion. Chem. Eng. Sci. 2006, 61, 5021-5029. [CrossRef]

4. Berman Abraham, S. Laminar flow in channels with porous walls. J. Appl. Phys. 1953, 24, 1232-1235. [CrossRef]

5. Sellars John, R. Laminar flow in channels with porous walls at high suction Reynolds numbers. J. Appl. Phys. 1955, 26, 489-490. [CrossRef]

6. Yuan, S.W. Further investigation of laminar flow in channels with porous walls. J. Appl. Phys. 1956, 27, 267-269. [CrossRef]

7. Terrill, R.M. Laminar flow in a uniformly porous channel with large injection. Aeronaut. Q. 1965, 16, 323-332. [CrossRef]

8. Kozinski, A.A.; Schmidt, F.P.; Lightfoot, E.N. Velocity profiles in porous-walled ducts. Ind. Eng. Chem. Fundam. 1970, 9, 502-505. [CrossRef]

9. Muthu, P.; Berhane, T. Mathematical model of flow in renal tubules. Int. J. Appl. Math. Mech. 2010, 6, 94-107.

10. Muthu, P.; Berhane, T. Flow through nonuniform channel with permeable wall and slip effect. Spec. Top. Rev. Porous Media Int. J. 2012. [CrossRef]

11. Muthu, P.; Berhane, T. Fluid flow in asymmetric channel. Tamkang J. Math. 2010, 42, 149-162. [CrossRef]

12. Berhane, T. Flow of a Newtonian fluid in a non-uniform wavy and permeable tube. New Trends Math. Sci. 2017, 4, 12-23. [CrossRef]

13. Chol, S.U.S.; Estman, J.A. Enhancing thermal conductivity of fluids with nanoparticles. ASME-Publ.-Fed 1995, 231, 99-106. 
14. Choi, S.U.; Zhang, Z.G.; Yu, W.; Lockwood, F.E.; Grulke, E.A. Anomalous thermal conductivity enhancement in nanotube suspensions. Appl. Phys. Lett. 2001, 79, 2252-2254. [CrossRef]

15. Buongiorno, J. Convective transport in nanofluids. J. Heat Transf. 2006, 128, 240-250. [CrossRef]

16. Li, Q.; Xuan, Y. Convective heat transfer and flow characteristics of Cu-water nanofluid. Sci. China Ser. E Technolgical Sci. 2002, 45, 408-416.

17. Kang, S.-W.; Wei, W.-C.; Tsai, S.-H.; Yang, S.-Y. Experimental investigation of silver nano-fluid on heat pipe thermal performance. Appl. Thermal Eng. 2006, 26, 2377-2382. [CrossRef]

18. Fotukian, S.M.; Esfahany, M.N. Experimental study of turbulent convective heat transfer and pressure drop of dilute $\mathrm{CuO} /$ water nanofluid inside a circular tube. Int. Commun. Heat Mass Transf. 2010, 37, 214-219. [CrossRef]

19. Kandelousi, M.S. KKL correlation for simulation of nanofluid flow and heat transfer in a permeable channel. Phys. Lett. A 2014, 378, 3331-3339. [CrossRef]

20. Sheikholeslami, M.; Rashidi, M.M.; Ganji, D.D. Effect of non-uniform magnetic field on forced convection heat transfer of $\mathrm{Fe}_{3} \mathrm{O}_{4}$-water nanofluid. Comput. Methods Appl. Mech. Eng. 2015, 294, 299-312. [CrossRef]

21. Sheikholeslami, M.; Gorji-Bandpy, M.; Ganji, D.D. Lattice Boltzmann method for MHD natural convection heat transfer using nanofluid. Powder Technol. 2014, 254, 82-93. [CrossRef]

22. Dreaden, E.C.; Alkilany, A.M.; Huang, X.; Murphy, C.J.; El-Sayed, M.A. The golden age: Gold nanoparticles for biomedicine. Chem. Soc. Rev. 2012, 41, 2740-2779. [CrossRef]

23. Lee, J.E.; Lee, N.; Kim, T.; Kim, J.; Hyeon, T. Multifunctional mesoporous silica nanocomposite nanoparticles for theranostic applications. Acc. Chem. Res. 2011, 44, 893-902. [CrossRef] [PubMed]

24. Barrak, H.; Saied, T.; Chevallier, P.; Laroche, G.; M'nif, A.; Hamzaoui, A.H. Synthesis, characterization, and functionalization of $\mathrm{ZnO}$ nanoparticles by $\mathrm{N}$-(trimethoxysilylpropyl) ethylenediamine triacetic acid (TMSEDTA): Investigation of the interactions between Phloroglucinol and ZnO@ TMSEDTA. Arab. J. Chem. 2019, 12, $4340-4347$. [CrossRef]

25. Ganesh, M.; Hemalatha, P.; Peng, M.M.; Jang, H.T. One pot synthesized Li, Zr doped porous silica nanoparticle for low temperature $\mathrm{CO}_{2}$ adsorption. Arab. J. Chem. 2017, 10, S1501-S1505. [CrossRef]

26. Mansha, M.; Khan, I.; Ullah, N.; Qurashi, A. Synthesis, characterization and visible-light-driven photoelectrochemical hydrogen evolution reaction of carbazole-containing conjugated polymers. Int. J. Hydrog. Energy 2017, 42, 10952-10961. [CrossRef]

27. Bush, A.W. Perturbation Methods for Engineers and Scientists; Routledge: Abingdon, UK, 2018.

28. Van Dyke, M. Perturbation Methods in Fluid Mechanics; Academic Press: New York, NY, USA, $1964 ;$ Volume 136.

29. Fakour, M.; Vahabzadeh, A.; Ganji, D.D. Study of heat transfer and flow of nanofluid in permeable channel in the presence of magnetic field. Propuls. Power Res. 2015, 4, 50-62. [CrossRef]

30. Khan, I.; Alqahtani, A.M. MHD nanofluids in a permeable channel with porosity. Symmetry 2019, 11, 378. [CrossRef]

(C) 2020 by the authors. Licensee MDPI, Basel, Switzerland. This article is an open access article distributed under the terms and conditions of the Creative Commons Attribution (CC BY) license (http:/ / creativecommons.org/licenses/by/4.0/). 